\title{
Dynamic Voltage Restorer and Review of Control Schemes Proposed For Dynamic Voltate Restorer
}

\author{
Deepa Patil \\ M. Tech Student, Department of Electrical Engineering, Bharati Vidyapeeth Deemed University, College of \\ Engineering, Pune - 411043
}

\begin{abstract}
For improving power quality as a cost effective solution for the protection of sensitive loads from voltage disturbances a dynamic voltage restorer (DVR) has great significance. Dynamic voltage restorers are mostly utilized to deal with voltage sag and swells in distribution systems. In this paper, a Dynamic voltage restorer and review of proposed control strategies applied in Dynamic voltage restorers are discussed.
\end{abstract}

Index term: Dynamic voltage restorer (DVR), harmonics, sag/swell, controller.

\section{Introduction}

Power quality is concerning issue for electric utilities and end users of electric power. This concern is mainly due to invention of load equipments with micro processor based controls and power electronic devices. Such load equipments are more sensitive to power quality variations than was used in the past. Power quality could be defined as the concept of powering and grounding sensitive electronic equipment in a manner suitable for the equipment [1].

Voltage sags and swells are considered as important power quality disturbances due to frequent occurrence and severe impact on sensitive loads. Several custom power devices are utilized to solve these problems. The most suitable and efficient device is dynamic voltage restorer (DVR). These power electronics converter based compensator is connected in series with the distribution feeder between the supply and the loads. Its main function is to mitigate any supply voltage disturbance especially voltage sag and swell, by inserting a voltage with the required magnitude, frequency and phase shift in order to restore load voltage to its rated values [2]. There are three basic control strategies for DVR [3]. These strategies are: 1) pre-sag compensation 2) In- phase compensation 3) Energy optimal compensation. The DVR must be able to compensate for voltages at loads that could be linear or non-linear or even distorted. Therefore, number of control techniques has been proposed in the literature.

In this paper as discussed above in section I is introduction. Section II, explains basic circuitry and operation of the DVR. In section III, various control schemes proposed for DVR are explained. And Section IV includes conclusion. Section V includes references.

\section{Dynamic Voltage Restorer}

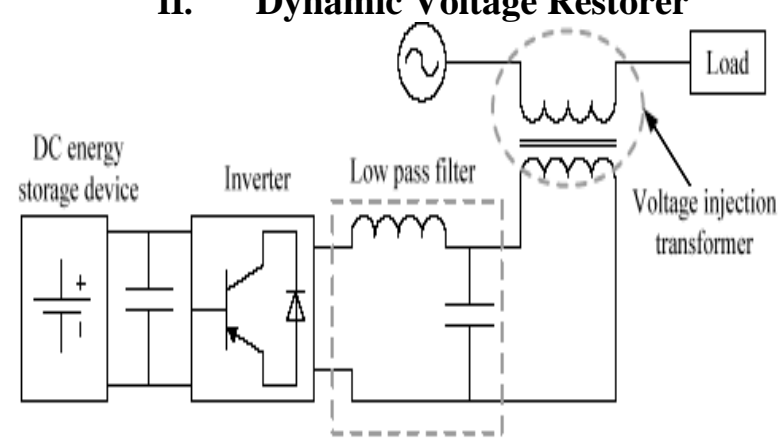

Source

Fig 1. Basic structure of DVR

As shown in fig 1 DVR consists four main parts - voltage source inverter, voltage injection transformer, DC energy storage device and low pass filter [4].

Voltage Source Inverter (VSI) - Function of VSI is to convert DC voltage supplied by energy storage device to an AC. VSI has usually low voltage and high current rating as step up injection transformers are used in DVR.

Voltage Injection Transformer - It is specially designed transformer which transforms and couples the injected compensating voltages generated by VSI to the incoming supply voltage. 
DC energy storage device - It provides real power requirement of DVR during compensation. Fly wheels, SMES, Super capacitors, batteries can be used as storage device.

Passive filter - It is used to filter out switching harmonic components from the injected voltage. It can be placed at inverter side or high voltage side of injection transformer.

\section{Review Of Proposed Control Schemes For Dynamic Voltage Restorer}

Phase locked loop (PLL) was used for control scheme of custom power devices to find information about phase angle and frequency of utility voltage[5].Under conditions such as voltage unbalance, flicker, harmonics frequency variations, PLL provide low distortion output by locking phase of utility voltage quickly. This PLL is hardware version that uses zero voltage crossing point detection method. However, this method is limited by its dynamic performance and noise around the zero voltage crossing point makes the output angle oscillate.

In [6] another method used the input voltage shifted by 900 . Limitations of this method are adequate accuracy and slow transient response due to the detection of zero crossing voltage during a half period.

For more faster and accurate phase control the concept of vector product PLL was proposed [7].It uses vector product-phase detector (VP-PD), PI controller, timer and memory. This software based VP-PLL method avoids the problems caused by the hardware comparator used in the hardware PLL. If the vector product is equal to zero, the three phase switching pattern becomes synchronised to the main supply voltage.

In [8] under a voltage unbalance condition, the positive sequence voltage was measured using a filter and the phase angle of the positive sequence was used. But used filter introduced a phase delay.

An instantaneous phase angle detection algorithm under voltage sag condition using the weighted leastsquares estimation method was proposed in [9]. By this method the positive and negative sequence voltages could be obtained without a delay. In [5] the concept based on space vector and d-q transformation, the software phase locked loop (SPLL) is proposed that could be implemented by using a digital signal processors (DSP). SPLL has been presented to realize a simple fast and robust method. Here, SPLL model that uses a lag/lead loop controller is derived in order to analyze the system performance and filtering characteristic by the use of bode diagrams and root locus methods.

Open loop control is used for DVR in [10].Different control methods to compensate voltage sags with phase jump are proposed and compared here. But the disadvantage of open loop control strategy used in DVR to regulate load voltage can produce poorly damped response due to the presence of switching harmonic filter in the restorer [11].

Multi loop controller is proposed in [11] to improve damping effect caused by switching harmonic filter. This proposed control scheme also permits a closer tracking of the reference load voltage under varied load conditions. To improve stability margins current mode control techniques along with outer voltage feedback loop is incorporated in to DVR control schemes. Hence, in addition with existing open loop controller, two feedback loops which utilize DVR load side voltage and filter capacitor current are considered in this proposed control scheme.

In [12] control scheme for cascaded HIGH VOLTAGE DVR is proposed. Here, cascaded HVDVR is controlled using a 2-DOF control scheme incorporating both $\mathrm{p}+$ resonant and posicast compensators, to achieve perfect reference voltage tracking and effective damping of the transient voltage oscillations.

To compute phase shift and voltage sag of supply voltage much quicker than other systems new matrix method is proposed in the [13]. This matrix vector control is utilized by main DVR control which considers only positive and negative sequence information in the supply. This type of control eliminates the need to control the zero sequence. The core of this controller is the Phase Locked Loop (PLL) which locks synchronous reference frame (d-q) to positive sequence component of the supply. This type of control is commonly known as spacevector control and the inverter pulse pattern strategy as space vector pulsewidth modulation (SVPWM).

Along with sag and swell harmonics is major power quality problem. To handle harmonics a novel controller is proposed in [14]. This proposed controller has a feed forward loop and two feedback loops. First feedback loop is used to actively increase the damping component of LC filter system to keep the output voltage overshoot within acceptable range. On the other hand, feed forward loop is used to compensate the voltage drop due to the feedback loop. Another feedback loop based on digital repetitive control algorithm is utilized to compensate the periodic harmonics of the load voltage, which may come from power converter, source and non linear load.

Based on analysis of physical limiters of the control bandwidth of DVR systems that use LC output using filters, controller is proposed in [15] for voltage compensation in DVR system. Without using nested loops, this controller achieves maximum control band-width up to the output filter cut-off frequency .so this proposed voltage controller allows good control dynamics. Proposed controller is implemented using a digital controller with processor. 
In [16] sliding mode control [SMC] strategy is summarized which is used in current control strategies for DVR including forward feed control and PI feedback control.

Dynamic Voltage Restorer based on hysteresis voltage control is proposed in [17]. To detect the magnitude and phase jump of voltage sag and swell Discrete Fourier Transform (DFT) is used. This strategy applies conventional two level hysteresis voltage control technique which is one type of non- linear voltage control based on the voltage error. Here, influence of hysteresis band on quality of load and DVR voltage is studied under voltage sag and swell.

A compensation voltage control scheme for DVR proposed in [18] is based on the Clark-Concordia transformation and PLL. The proposed PLL structure is based on the sliding mode controller due to its fast dynamic response, robustness and system order reduction. Input- output linearization is proposed control method for DVR power converter.

In [19] control scheme which deals with voltage sag, harmonic voltages and voltage imbalances simultaneously within a bandwidth is proposed for DVR. It consists a feed-forward term to improve the transient response and feedback term to enable zero error in steady state. Important aspect of this control scheme is only one controller is required to eliminate the power quality disturbances discussed above. Controller can be implemented using either rotating reference frame or a stationary reference frame.

DVR based on firing control strategy for the six-switch voltage source is proposed in [4]. In this firing control scheme, one of the three inverter legs is to be intentionally opened, one per time in pre-planned sequence. 1500 conduction mode is generated by combining 1800 and 1200 conduction modes. With this proposed scheme, a seven level, 12 step output voltage waveforms which resemble the sinusoidal wave-shape are primarily obtained by inverter. This reduces the harmonic contents highly which are involved in injecting voltage wave forms. Thus, DVR with this proposed control strategy gain more voltage boosting controllability in both voltage level and time response.

In [20] voltage sag detection algorithm and control algorithm synthesis of DVR are proposed. The proposed control scheme includes the grid synchronization algorithm based on the double synchronous reference frame PLL (DSRF-PLL), the reference compensation voltages generation, the shunt converter control algorithm and the series inverter control algorithm.

\section{Conclusion}

Brief review for control schemes proposed for DVR is taken in this paper.DVR with basic circuitry is also explained in detail.

\section{References:}

[1]. R.C.Dugan, M.F. McGranaghan, H.W. Beatly, "Electrical Power Systems Quality", McGraw-Hill, 1996.

[2]. A.Ghosh, G.Ledwich, "Compensation of distribution system voltage using DVR", IEEE Trans Power delivery, Vol.17, PP. 10301036 , Oct 2002.

[3]. J.G.Nielson, F.Balaajerg, "Comparison systems topologies for dynamic voltage restoration", in proc.IEEE/IASO1 conference, 2001, PP.2397-2403.

[4]. Ahmed A. Helal, Mohamed H. Saied, "Dynamic Voltage Restorer Adopting $150^{\circ}$ Conduction Angle VSI", 2008 IEEE Electrical Power and Energy conference.

[5]. Changjiang Zhan, C.Fitzer, V.K.Ramchandramurthy, A.Arulampalam, M.Barnes, N.Jenkins, "Software Phase Locked Loop Applied To Dynamic Voltage Restorer", in proc. IEEE-PES Winter Meeting 2001, PP. 1033 - 1038

[6]. D.H.Wolaver,"Phase Locked Loop Circuit Design", Englewood cliffs, Prebtice, 1991.

[7]. G.H.Jung,G.C.Cho,G.H.Cho, "Improved Control For High Power Static Var Compensator Using Novel Vector Product Phase Locked Loop(VP-PLL)", International Journal of Electronics,Vol .86,No.7,1999, PP. 837-855.

[8]. P.N.Enjeti, S.A.Choudary," A New Control Strategy To Improve The Performance Of a PWM AC To DC Converter Under Unbalanced Operating Conditions", IEEE Trans Power Elect. Vol.8, No.4,PP. 493-500, Oct-1993.

[9]. Hong-Seok Song, Hyun-gyu Park,Kwanghee Nan, “An Instantaneous Phase Angle Detection Algorithm Under Unbalanced Line Voltage Condition", Proceedings of IEEE PESC,99.

[10]. J.G. Neilsen, F.Blaabjerg, "Control Strategies for Dynamic Voltage Restorer Compensating Voltage Sags With Phase Jump", in proc IEEE APEC'01,Vol.2,2001, PP.1267-1273.

[11]. Mahinda Vilathgamuwa, A.A.D.Ranjith Parera, S.S.Choi, "Performance Improvement Of the Dynamic Voltage Restorer With Closed Loop

Load

[12]. Voltage and Current Mode Control", IEEE Transactions on Power Electronics, Vol.17, No.5. Sept 2002, PP.824-834.

[13]. Poh Chiang Loh,D Mahinda Vilathgamuwa,Seng Khai Tang,Hian Lih Long, "Multilevel Dynamic Voltage Restorer", IEEE POWER ELECTRONICS LETTERS,Vol.2, No.4, Dec 2004,pp.125-130.

[14]. C.Fitzer, M.Barnes,P.Green, "Voltage Sag Detection Technique For Dynamic Voltage Restorer", IEEE Transaction On Industry Applications, Vol.40,No.1,JAN/FEB 2004, PP.203-212

[15]. Young-Hoon Cho, Seung-Ki Sul, "Controller Design for Dynamic Voltage Restorer With Harmonics Compensation Function", Industrial Applications Conference, 2004, 39 ${ }^{\text {th }}$ IAS meeting Conference Record of 2004 IEEE, PP.1452-1457, Vol.3.

[16]. Hyosung Kim,Seung-Ki Soul, "Compensation Voltage Control in Dynamic Voltage Restorer By Use of Feed Forward and State Feedback Scheme”, IEEE Transaction on Power Electronics, Vol.20, No.5, Sept 2005, PP. 1169-1177.

[17]. Pie Ruilin, Zhao Yuegen, "Sliding mode Control Strategy of Dynamic Voltage Restorer ",International Conference On Industrial Electronics and Control Applications,2005,Publisher IEEE,PP.3.

[18]. Fawzi AL Jowder, "Modelling and Simulation of Dynamic Voltage Restorer Based On Hysteresis Voltage Control", $33^{\text {rd }}$ Annual Conference of the IEEE Industrial Electronics Society (IECON), Nov.5-8,2007,PP.1726-1731. 
[19]. V.Fernao Pires, Gil Marques,J.F. Martins,J.Fernando Silva, "Dynamic Voltage Restorer Using a New Compensation Voltage Control and Converter Based Input Output Linearization", IEEE REGION 8,SIBIRCON 2008,PP.139-144.

[20]. Pedro Roncero -Sanchez, Jose Enrique Orgeta-Calderon,Aurelio Garcia-Cervada, "A Versatile Control scheme for a Dynamic Voltage Restorer For Power Quality Improvement”, IEEE Transaction On Power Delivery, Vol.24,No.1, Jan 2009,PP.277-284.

[21]. 20)Lin Xu, Yang Han, "Effective Controller Design For The Dynamic Voltage Restorer For Sag Mitigation In Distribution Utilities", ELEKTROTEHISKI VESTNIK 78(5):304-311, 2011.ENGLISH EDITION 